\title{
The Impacts of the Personality Attribute of Time and Money on Customer Engagement Behavior: A Self-concept Perspective
}

\author{
Xinxin $\mathrm{Chen}^{1} \&$ Hongyan $\mathrm{Yu}^{2}$ \\ ${ }^{1}$ Business School, Changzhou University, Changzhou, China. \\ ${ }^{2}$ Business School, Sun Yat-Sen University, Guangzhou, China. \\ Correspondence: Xinxin Chen, Business School, Changzhou University, Changzhou, No.21, Gehuzhong Road, \\ China.
}

Received: May 4, 2020

doi:10.5539/ibr.v13n7p14

\author{
Accepted: May 22, 2020 \\ Online Published: May 27, 2020 \\ URL: https://doi.org/10.5539/ibr.v13n7p14
}

\begin{abstract}
Although recent studies have explored the antecedents of customer engagement behavior (CEB), few empirical studies have explored the mechanisms that connect these antecedents to CEB. From self-concept perspective, this research uses experimental and survey methods to explore the influence of the type of customer-invested resource (time vs. money) and customers' regulatory focus (promotion-focused vs. prevention-focused) on CEB and the mechanisms that underlie these processes. The results of three studies show that promotion-focused customers initiate more recommendations and complaints when time (vs. money) spent in the shopping experience is emphasized, whereas this effect does not exist for prevention-focused customers. A self-concept connection mediates the moderating role of regulatory focus in the relationship between types of resources and recommendations, whereas this mediating role of self-concept connection does not exist with complaining behaviors. In summary, the influence of customer-invested resources on CEB varies according to a customer's regulatory focus.
\end{abstract}

Keywords: time, money, regulatory focus, customer engagement behavior (CEB), self-concept connection

\section{Introduction}

In the past, most product/service information came from marketers. However, with the rapid development of the Internet and social media, customers now have more control over product and service information through increased access to word-of-mouth, customer reviews, customer referrals, and so on (Lee, 2012). Therefore, customer behavior such as word-of-mouth, customer reviews, and customer referrals has become increasingly important for business success. These behaviors are labeled "customer engagement behaviors (CEBs)," which refer to customers' behavioral manifestations toward a brand or firm beyond merely purchasing, resulting from motivational drivers (Van Doorn et al., 2010). Increasingly researchers and companies are becoming aware of the important role of CEB in a business's performance (Rust, Lemon \& Zeithaml, 2004).

As the role of CEB in marketing is rapidly becoming more important, it is necessary to explore what factors influence the occurrence of the CEB. Many previous studies have explored factors affecting CEBs (e.g., De Matos \& Rossi, 2008). These factors include customer-based factors (e.g., customer goals, customer-invested resources), firm-based factors (e.g., brand characteristics, firm reputation) and context-based factors (e.g., media attention) (Van Doorn et al., 2010). Customer-invested resources are important customer-based factors. And time and money are two fundamental resources in a consumer landscape (Mogilner \& Aaker, 2009). In a shopping experience, the investment of time and money becomes the benchmark for customers to evaluate their own behavior. Thus, time and money investment may affect CEB. However, few empirical studies have explored how customer's time and money investmentsaffect CEBs. This paper will explore the relationship between customer-invested resources (time vs. money) and CEBs from self-concept perspective.

Based on self-concept perspective, customer CEBs reflect how customers view products or brands as a part of their self-concepts (Van Doorn et al., 2010). A self-concept can be viewed as a set of self-schemas representing stable knowledge structures about the self that organize incoming self-related information and help people make sense of themselves in their environment (Markus, 1977). In this framework, CEB focuses on the behavioral consequences of the psychological processes embedded in customer and brand connections (i.e., self-concept 
connection) (Van Doorn et al., 2010). Thus, from this perspective, CEB is an expression of a customer's self-concept. For time and money, previous studies have shown that when people's concepts of time and/or money are motivated, their self-concepts will also be activated (e.g., Haggard et al., 2002; Prince, 1993; Zhang, 2009; Vohs et al., 2006, 2008; Mogilner, 2010; Mogilner \& Aaker, 2009). From this perspective, the current research proposes that the customer's self-concept connections to products/brands are the underlying mechanisms that connect customer-invested resources (time vs. money) to CEB. This paper will explore this hypothesis and explore whether customer investment of time and money has different effects on CEB.

\section{Theoretical Foundation and Hypotheses}

\subsection{CEB and Self-Concept Connection}

CEBs are customer behavioral manifestations toward a brand or firm, beyond the act of purchasing, resulting from motivational drivers (Van Doorn et al., 2010). CEBs include many behaviors, such as blogging, tweeting, online reviews, voice, word-of-mouth, and so on. Considering valence from the firm's perspective, CEB can be classified as positive or negative (Brady, Voorhees, Cronin Jr, \& Bourdeau, 2006). Positive CEBs, such as recommendations, occur when a customer's experience exceeds his or her expectations of a product/service. Negative CEBs, such as complaints, occur when a customer has an unsatisfactory experience with a product/service. This research will use recommendations and complaints as indicators of positive and negative CEBs.

CEB is mainly affected by three types of factors: customer-based factors, firm-based factors, and context-based factors (Van Doorn et al., 2010). Some of the customer-based factors affecting CEB are customer attitudinal antecedents (e.g., customer satisfaction, brand commitment), customer goals (e.g., maximizing consumption/relational benefits), customer personality characteristics (e.g., self-enhancement, regulatory focus), affective states (e.g., disappointment, anger), and customer invested resources (e.g., time, money) (Van Doorn et al., 2010). At present, few empirical studies have explored the customer-based factors that affect CEB, especially customer-invested resources. Customers are the generators of CEB; therefore, customers invested resources play an important role in CEB.This research explores the effects of time and money on CEB and the underlying mechanisms that connect them to CEB.

As mentioned above, CEB focuses on the behavioral consequences of the psychological processes embedded in customer's self-concept connection to a brand or firm. A self-concept connection is a dimension of the consumer-brand relationship, which measures the degree to which a brand contributes to one's identity, values, and goals (Fournier, 1998). Further, a self-concept connection reflects how a product or brand becomes a part of a customer's self-concept. Previous studies have found that self-concept connection can increase a customer's brand loyalty (Hwang \& Kandampully, 2012). If the customer establishes a self-concept connection to a brand or firm, he/she will find it easier to launch CEB. For those customers who establish a self-concept connection to a brand or firm, they will initiate more positive CEB (e.g., recommendations) in satisfactory shopping experience and/or more negative CEB (e.g., complaints) in dissatisfactory shopping experience. In other words, we propose that the self-concept connection to products/brands is the underlying mechanism of CEB.

\subsection{Time, Money and CEBs}

Time and money are two fundamental resources in a consumer landscape (Mogilner \& Aaker, 2009). Previous studies have confirmed the link between the concept of money and self-concept. For example, Vohs et al. (2008) found that money is bad for the interpersonal self but can be good for the personal self. Vohs et al. (2006) concluded that people would feel self-sufficiency when activated the concept of money. Zhang (2009) verified the relationship between money and self-esteem. Belk (1988) argued that money is a special possession as self-extensions. Similarly, time also can activate people's self-concepts. Wittmann (2009) suggested that time is a function of the self. Haggard et al. (2002) offered an empirical illustration of the link between self and time perception. Previous studies have highlighted the link between time and self-concepts (Carstensen, Isaacowitz \& Charles, 1999; Liu \& Aaker, 2007; Mogilner \& Aaker, 2009).

However, the degrees of self-concept activated by time and money may be different. A large number of studies have shown that the values of time and money depend on individual characteristics (e.g., personal experiences, identity, emotions), which affect the allocation of these two resources (Reed, Aquino \& Levy, 2007; Saini \& Monga, 2008; Soman \& Lam, 2002; Zauberman \& Lynch Jr, 2005). In general, people tend to choose risk-seeking options when money may be lost, whereas they tend to choose relatively risk-averse options involving the loss of waiting time (Leclerc, Schmitt \& Dube, 1995). Merely mentioning time rather than money may lead to different consequences (Reed, Aquino \& Levy, 2007). The effects of asking for time are different than the effects of asking for money because the significance of time and money is not identical. Spending 
money tends to create more the feeling of ownership or reflect the usefulness of the product, whereas spending time tends to be more an expression of self-concept (Mogilner, 2010; Mogilner \& Aaker, 2009). Activating the construct of time heightens customers' self-concept connection to the product/brand, which leads to customer engagement (Mogilner, 2010; Mogilner \& Aaker, 2009). In contrast, activating money tends to be less representative of self-concept (Reed, Aquino \& Levy, 2007). Thus, the following hypothesis wasproposed:

H1: Customer will generate greater self-concept connections to a product or brand when the time investment (vs. money investment) is emphasized in a shopping experience.

As mentioned above, CEB is an expression of self-concept. And customer's time investment will activate more self-concept connection to the product/brand than money investment. Therefore, we propose that customer's time investment (vs. money investment) will be likely to generate more CEBs through self-concept connections to product/brand in shopping experiences. In other words, customer invests different resources (time vs. money) will generate different CEBs. However, this effect may affect by customer's character traits, such as regulatory focus.

\subsection{Regulatory Focus: The Moderator}

The "time vs. money effect" on CEBs may affect by customer's regulatory focus. Regulatory focus is an important customers' personality characteristics. Regulatory focus theory views regulatory focus as a self-regulation process through which people seek to align their behavior with relevant goals and standards (Higgins, 1997). The theory includes two different self-regulation systems: promotion-focused and prevention-focused systems. Customer regulatory focuses (promotion-focused vs. prevention-focused) are situational factors (i.e., states) which can be elicited by cues embedded in the task or context, as well as relatively stable personality traits (Daryanto, de Ruyter, Wetzels, \& Patterson, 2010; Higgins, 1997). Typically,regulatory focuses can be stimulated with priming techniques (temporary state) or measured through self-reported measurements (trait) (Higgins et al., 2001; Lockwood, Jordan \& Kunda, 2002). Promotion-focused individuals want to achieve "ideal selves," whereas prevention-focused individuals want to achieve "ought selves." Promotion-focused individuals are trying to achieve their hopes and aspirations, whereas prevention-focused individuals focus on their duties and obligations. Promotion-focused people tend to use pro-active strategies to attain their goals; prevention-focused people tend to use vigilance-based strategies to attain their goals (Higgins, 1997). Essentially, CEBs (e.g., tweeting, online reviews, word-of-mouth) are a customer's active behaviors. Therefore, promotion-focused customers will initiate more CEBs and prevention-focused customers will initiate fewer CEBs, regardless of whether they are positive or negative.

This paper explores the impacts of the personality attributes of time and money (self-concept connection) on CEB. As mentioned above, this research predicts that when the customers' time (vs. money) investment is emphasized in a product or brand, they will generate a stronger self-concept connection and subsequently more CEBs.The current research further predicts that promotion-focused customers will initiate more CEBs, and prevention-focused customers will initiate fewer CEBs. Putting these predictions together, this research predicts that the different effects of time versus money on CEBs will be moderated by customers' regulatory focus. Specifically, the time versus money effect will only happen with promotion-focused customers, and this effect will not exist for prevention-focused customers. Because prevention-focused customers tend to initiate fewer CEBs, the difference between CEBs when time and money investment was emphasized may be very small (a floor effect). Thus, the time vs. money effect will not exist for prevention-focused customers. However, promotion-focused customers tend to initiate more CEBs, and a difference between CEBs when time and money investment are emphasized is expected to emerge. Thus, the following hypothesis was set up:

H2: Regulatory focus will moderate the relationship between customer-invested resources (time vs. money) and CEBs. Specifically, promotion-focused customers will initiate more CEBs when the investment of time (vs. money) is emphasized in products/services experiences, whereas prevention-focused customers will initiate the same number of CEBs for investments of either time or money.

In addition, CEB can be viewedthe expression of a customer's self-concept. Customers' invested resources (time vs. money) influence the expression of self-concept, then their CEBs. We propose that the self-concept connection to products or brands is the mechanism of CEB. Thus, the time vs. money effect of promotion-focused customers on CEB may be mediated by the self-concept connection. Therefore, we predict that the self-concept connection will mediate the joint effect of customer-invested resources (time vs. money) and regulatory focuses (promotion-focused vs. prevention-focused) on CEB. Thus, the following hypothesis was set up:

H3: Self-concept connections will mediate the moderating role of regulatory focus in the relationship between 
customer-invested resources (time vs. money) and CEBs.

\subsection{Theoretical Framework}

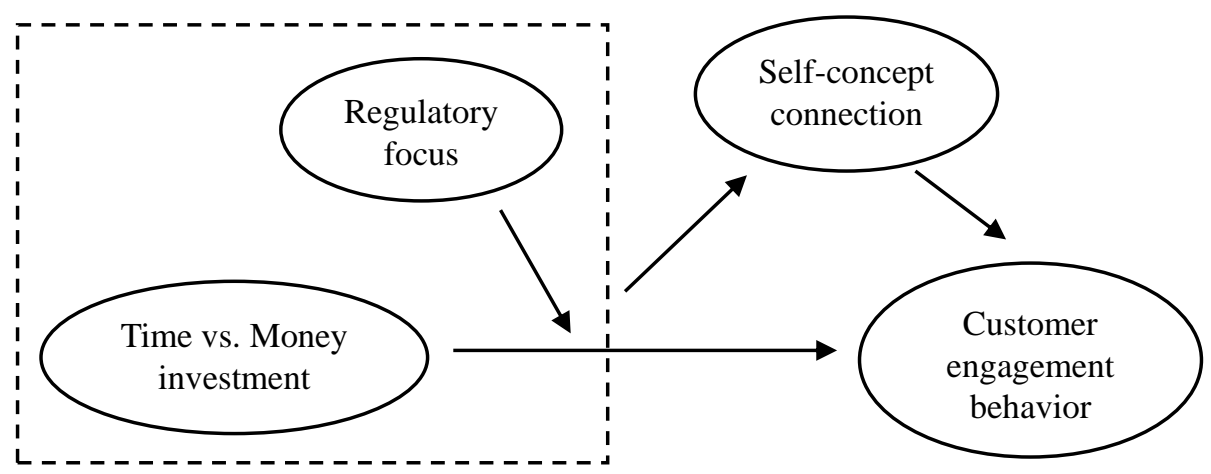

Figure 1. The joint effect of resourcetypeand regulatory focus on CEB

Overall, the theoretical framework of this research is illustrated in Figure 1. Customers' regulatory focuses (promotion-focused vs. prevention-focused) moderates the relationship between the type of customer-invested resources (time vs. money) and CEBs, and this moderating effect is mediated by customers' self-concept connections. Three studies then were used to test these hypotheses.

\section{Study 1}

\subsection{Study Design}

Study 1 investigated whether customers would manifest different self-concept connections for the products/services when they invested different types of resources (time vs. money) in shopping experiences. This study used four questionnaire versions to explore customer's shopping experience that customers invested much time, little time, much money, and little money, respectively. Each version of the questionnaire was divided into three sections. The first section collected basic demographic information. The second section investigated the latest shopping experience during which the participants had invested much time/money or little time/money in nearly 3 months. The participants were asked to briefly write down the process and time/money of purchase. They were then asked the likeability to the goods that they had spent much time/money (little time/money) shopping for ( $1=$ very dislike, $5=$ very like). The third section used the revised self-concept connection scale to measure participants' self-concept connections to the goods. The self-concept connection scale $(\alpha=0.81$, $C R=0.82$ )was revised from Fournier (1998) brand relationship quality scale (see Appendix A).

Eight hundred Chinese people (200 people in each condition) responding to our Internet survey and 558 (69.75\%) provided valid responses. Most of the respondents were female (59.14\%), between 20 and 40 years old (91.04\%), middle-income (3000-10000 yuan/mo., 64.88\%), highly educated (95.53\%), and enterprise or public employees $(63.26 \%)$.

\subsection{Results}

Manipulation test was conducted firstly. The time invested in "much time group" ( $M=4.10$ hour, $S D=9.59)$ was significantly more than that in "little time group" $(M=1.01$ hour, $S D=1.00), t(280)=3.64, p<0.001$. The money invested in "much money group" $(M=1933.46$ yuan, $S D=2036.09)$ was significantly more than that in "little money group" ( $M=97.24$ yuan, $S D=129.63), t(274)=10.22, p<0.001$. These results show that the independent variable manipulation in this study is successful.

Table 1 shows the results for likeability and self-concept connection under the four conditions. The likeability of products in four groups were significant different $(F(3,554)=11.28, p<0.001)$. The likeability in group $1(M=4.19$, $S D=0.63)$ was greater than that in group $3(M=3.99, S D=0.67)$; the likeability in group $2(M=4.25, S D=0.58)$ was greater than that in group $4(M=3.85, S D=0.69)$; the likeability in group 1 was not different from that in group 2; the likeability in group 3 was not different from that in group 4. For self-concept connection scores, The difference among four groupswas significant $(F(3,554)=5.87, p<0.01)$. The score in group $1(M=18.15, S D=3.57)$ was greater than that in group $3(M=17.09, S D=4.13)$; the score in group $2(M=18.39, S D=3.81)$ was greater than that in group $4(M=16.76, S D=3.95)$; the score in group 1 was not different from that in group 2; the score in group 3 was not different from that in group 4. 
Table 1. Likeability and self-concept connection scores in four groups

\begin{tabular}{cccc}
\hline Groups & Number & Likeability & $\begin{array}{c}\text { Self-concept } \\
\text { connection }\end{array}$ \\
\hline Group 1 (Invested much time) & 153 & $4.19(0.63)$ & $18.15(3.57)$ \\
Group 2 (Invested much money) & 147 & $4.25(0.58)$ & $18.39(3.81)$ \\
Group 3 (Invested little time) & 129 & $3.99(0.67)$ & $17.09(4.13)$ \\
Group 4 (Invested little money) & 129 & $3.85(0.69)$ & $16.76(3.95)$ \\
\hline
\end{tabular}

Note: Standard deviations aregiven in parentheses.

This study then explores the relationship between self-concept connection and likeability. The results showed that likeability was regressed against self-concept connection $(\beta=0.33, t(557)=8.12, p<0.001)$.

\subsection{Discussion}

The results of study 1 showed that customers generate more self-concept connections when they invested much time/money in shopping experience than that when they invest little time/money. And the self-concept connections were not different between customer invested much time group and customer invested much money group. These results did not support H1. These results may suggest time and money investments have the same effect on customer's self-concept connection in the shopping experience.

Study 1 showed the personality attributes of time and money (i.e., self-concept connection) in the shopping experience. However, the self-concept connection caused by time investment was not different from that caused by money investment. This result is not consistent with the theory hypothesis in this paper. This paper assumes that the regulatory focus will moderate the relationship between customer resources (time vs. money) investment and CEB. Whether the result of study 1 is also caused by regulatory focus? Study 3 will further explore whether customer's time and money investments would manifest different self-concept connections in promotion-focused (or prevention-focused) customers.

\section{Study 2}

\subsection{Study Design}

Study 2 examined the moderating role of regulatory focus in the relationship between customer-invested resources (time vs. money) and CEBs. This study had a 2 (customer-invested resources: time vs. money) x 2 (regulatory focuses: promotion-focused vs. prevention-focused) between-subjects design. The dependent variable was the likelihood of a customer complaining (negative $\mathrm{CEB}$ ) and making a recommendation (positive CEB) to a good friend.

One hundred and thirty-two Chinese undergraduates were randomly assigned to one of four groups. Each group had 33 participants. Regulatory focuseswere primed by asking the participants to think about and write down their recent hopes and aspirations (promotion-focused) or their recent duties and obligations (prevention-focused) in their lives (Freitas \& Higgins, 2002). The participants were further asked to write down how they would achieve their hopes and aspirations or fulfill their duties and obligations.

Following the regulatory focus manipulation, this study manipulated customer-invested resources (time vs. money) and shopping experiences (satisfactory vs. unsatisfactory) with a scenario simulation. There were four scenarios in this experiment: (a) Time and Satisfaction, (b) Time and Dissatisfaction, (c) Money and Satisfaction, and (d) Money and Dissatisfaction. Each participant completed either (a) and (b) or (c) and (d). The satisfaction and dissatisfaction scenarios were counterbalanced among the participants. In the Time and Satisfaction scenario, participants were asked to imagine the following situation:

"There are many brands for a product on the market. With the development of online stores, consumers now can easily compare multiple brands at the same time. Now imagine you want to buy a coat. To save time, you decide to buy a coat on the Internet. You compare different brands in six online shops. You spend a lot of time comparing prices, styles, colors and so on. In the end, you spend nearly four hours before choosing a coat (coat A). Two days later, you receive coat A, which cost you a lot of time. You are very satisfied with this coat. You believe coat A is perfect. You believe that coat A is worth the time you invested."

The Time and Dissatisfaction scenario was similarto the Time and Satisfaction scenario, but the result of the purchase was different. In the Time and Dissatisfaction scenario, "You are very unsatisfied with this coat. You believe coat A has many defects, and that coat A was not worth the time you invested." The Money and Satisfaction and Money and Dissatisfaction scenarios were comparable to the Time and Satisfaction and Time 
and Dissatisfaction scenarios, respectively, except these two scenarios emphasized the money invested in the shopping experience.

Finally, in the satisfactory scenarios, the participants were asked "One of your good friends wants to buy a new coat. What is the probability that you would recommend coat A to him/her?" In the unsatisfactory scenarios,the participants were asked, "One of your good friends wants to buy a new coat. What is the probability that you would complain about coat A and tell him/her not to buy the product?" To answer the last question, the participants selected one of 11 probability ranges from $0 \%$ to $100 \%$.

\subsection{Results}

Three independent raters who did not participate in the experiment coded the content of the narratives written by the participants, and assessed whether the content reflected participants'hopes and aspirations or duties and obligations, as requested. Eight participants were excluded from the analysis because their contents did not reflect hopes and aspirations or duties and obligations. The data for 124 participants (48 male) were included in the final analysis. Table 2 shows the probabilities of recommendations or complaints occurring under each condition.

Table 2.The probabilities of recommendations and complaintsin four groups

\begin{tabular}{lcccc}
\hline \multirow{2}{*}{ Regulatory focus } & \multicolumn{2}{c}{ Promotion-focused } & \multicolumn{2}{c}{ Prevention-focused } \\
\cline { 2 - 5 } & Investedtime & Investedmoney & Investedtime & Investedmoney \\
\hline Probability of recommendation & $83.23 \%$ & $69.33 \%$ & $64.19 \%$ & $72.19 \%$ \\
& $(18.87 \%)$ & $(23.63 \%)$ & $(25.92 \%)$ & $(17.91 \%)$ \\
Probability ofcomplaint & $83.87 \%$ & $69.00 \%$ & $65.16 \%$ & $72.81 \%$ \\
& $(24.04 \%)$ & $(32.09 \%)$ & $(25.54 \%)$ & $(21.29 \%)$ \\
Number & 31 & 30 & 31 & 32 \\
\hline
\end{tabular}

Note: Standard deviations aregiven in parentheses.

For the probability of recommendation, a 2 (regulatory focus: promotion-focused vs. prevention-focused) x 2 (invested resource: time vs. money) ANOVA showed that the interaction between regulatory focus and invested resources was significant $(F(1,120)=7.82, p<0.01)$; the main effect of regulatory focus $(F(1,120)=4.27, p<0.05)$ was significant, but the main effect of invested resource $(F(1,120)=0.57, p>0.05)$ was not significant. Simple effect tests showed that for promotion-focused participants, the recommendation likelihood when time investment was emphasized $(M=83.23 \%, S D=18.87 \%)$ was greater than when money investment was emphasized $(M=69.33 \%, S D=23.63 \%, F(1,121)=6.15, p<0.05)$, whereas for prevention-focused participants, the recommendation likelihood when time investment was emphasized $(M=64.19 \%, S D=25.92 \%)$ was not different from when money investment was emphasized $(M=72.19 \%, S D=17.91 \%, F(1,121)=2.00, p>0.05)$.

For the probability of complaint, the interaction between regulatory focus and invested resources was significant $(F(1,120)=5.83, p<0.05)$, but the main effects of regulatory focus $(F(1,120)=2.55, p>0.05)$ and invested resource $(F(1,120)=0.60, p>0.05)$ were both not significant. Simple effect tests showed that for promotion-focused participants, the complaint likelihood when time investment was emphasized $(M=83.87 \%, S D=24.04 \%)$ was greater than when money investment was emphasized $(M=69.00 \%, S D=32.09 \%, F(1,121)=5.03, p<0.05)$, whereas for prevention-focused participants, the complaint likelihood when time investment was emphasized $(M=65.16 \%, S D=25.54 \%)$ was not different from when money investment was emphasized $(M=72.81 \%$, $S D=21.29 \%, F(1,121)=1.31, p>0.05)$.

\subsection{Discussion}

For promotion-focused customers, the probabilities of making recommendations and complaints when time investment was emphasized were greater than when money investment was emphasized. For prevention-focused customers, the probabilities of making recommendations and complaints when time investment was emphasized were not different from when money investment was emphasized. These results support $\mathrm{H} 2$. Note that when time (vs. money) investment was emphasized, promotion-focused customers significantly increased both positive (e.g., recommendations) and negative (e.g., complaints) CEBs. Therefore, emphasizing customers' time investment may be a double-edged sword for firms, as emphasizing customers' time investments will only benefit firms that provide customers with a satisfactory shopping experience. 


\section{Study 3}

\subsection{Study Design}

Based on study 2, study 3 explored whether self-concept connection is the underlying mechanism of recommendation and complaint behaviors. This study used two questionnaire versions to collect the needed data. One version emphasized the time that customers invested in the shopping experience, and the other emphasized the money that customers invested in the shopping experience. Each participant was randomly assigned to complete one version of the questionnaire. Each version of the questionnaire was divided into four sections. The first section collected basic demographic information. The second section investigated shopping experiences during which the participants had invested a lot of time/money. The participants were asked about both satisfactory and unsatisfactory shopping experiences. An unrelated distraction task (20 simple calculation questions) was inserted between the two experiences. The order of the shopping experiences was counterbalanced among the participants. The third section used the revised self-concept connection scale in study 1 to measure participants' self-concept connections to the goods/brands that they had spent a lot of time/money shopping for. The last section measured participants' regulatory focus using the modified regulatory focus questionnaire (RFQ) $(\alpha=0.80, C R=0.90)$ from Higgins et al. (2001) regulatory focus questionnaire (RFQ) (see Appendix B).

The second section of the questionnaire examined the shopping experience as follows. Participants were first asked to recall satisfactory/unsatisfactory shopping experiences in which they had spent a lot of time/money. Then they were asked to briefly write down one of the experiences. Following that, they were asked to assess how many such experiences they had had ( $1=$ very little; $5=$ very many). Next, they were asked the question: "For those satisfactory/unsatisfactory goods/services that you spent a lot of time/money on, have you recommended/complained about the goods/services (or brands, companies) to people around you (such as friends, family, classmates, roommates, etc.)?" The answer to the question was assigned a score on a five-point scale ranging from "never complained/recommended (1)" to "complained/recommended every time (5)." Finally, this study measured how important they believed their time/money was ( $1=$ very unimportant, $5=$ very important).

Three hundred and twenty-six participantsin China were recruited to participate in this study. Two hundred and eighty-four participants provided valid responses; 42 participants were excluded because they did not provide complete responses or they had "very little" or "little" shopping experience. Next, the promotion-focused and prevention-focused groups were defined as the participants with regulatory focus scores that were 0.5 standard deviation above the mean (76 people) and 0.5 standard deviation below the mean ( 75 people), respectively. Therefore, 151 participants were included in the final analysis. These participants were mostly between 18 and 25 years old $(79.47 \%)$, and 71 were male $(47.02 \%)$.

\subsection{Results}

Table 3 showed the results for recommendation behavior, complaint behavior, and self-concept connections under the four conditions. For the frequency of recommendations, a 2 (regulatory focus: promotion-focused vs. prevention-focused) x 2 (invested resource: time vs. money) ANOVA showed that the interaction between regulatory focus and invested resources was significant $(F(1,147)=8.01, p<0.01)$; the main effect of regulatory focus $(F(1,147)=27.57, p<0.001)$ was significant, but the main effect of invested resource $(F(1,147)=2.69$, $p>0.05$ ) was not significant. Simple effect tests showed that for promotion-focused participants, the recommendation frequency when time investment was emphasized $(M=3.36, S D=1.01)$ was greater than when money investment was emphasized $(M=2.62, S D=1.01, F(1,148)=9.06, p<0.01)$, whereas for prevention-focused participants, the recommendation frequency when time investment was emphasized $(M=2.03, S D=1.01)$ was not different from when money investment was emphasized $(M=2.22, S D=1.02, F(1,148)=0.83, p>0.05)$.

Table 3. Recommendation,complaint,and self-concept connection scores

\begin{tabular}{lcccc}
\hline & \multicolumn{2}{c}{ Invested time } & \multicolumn{2}{c}{ Invested money } \\
\cline { 2 - 5 } Regulatory focus & Promotion-focused & Prevention-focused & Promotion-focused & Prevention-focused \\
\hline Recommendation & $3.36(1.01)$ & $2.03(1.01)$ & $2.62(1.01)$ & $2.22(1.02)$ \\
Complaint & $2.72(1.05)$ & $2.10(0.82)$ & $2.16(0.76)$ & $2.42(1.03)$ \\
Self-concept connection & $17.67(3.25)$ & $16.41(3.15)$ & $15.00(4.41)$ & $17.11(3.29)$ \\
Number & 39 & 39 & 37 & 36 \\
\hline
\end{tabular}

Note: Standard deviations aregiven in parentheses. 
For the frequency of complaint, the interaction between regulatory focus and invested resources was significant $(F(1,147)=8.37, p<0.01)$, but the main effects of regulatory focus $(F(1,147)=1.44, p>0.05)$ and invested resource $(F(1,147)=0.65, p>0.05)$ were not significant. Simple effect tests showed that for promotion-focused participants, the complaint frequency when time investment was emphasized $(M=2.72, S D=1.05)$ was greater than when money investment was emphasized $(M=2.16, S D=0.76, F(1,148)=6.96, p<0.01)$, whereas for prevention-focused participants, the complaint frequency when time investment was emphasized $(M=2.10, S D=0.82)$ was not different from when money investment was emphasized $(M=2.42, S D=1.03, F(1,148)=2.26, p>0.05)$.

When self-concept connection was analyzed as the dependent variable, the interaction between regulatory focus and invested resources was significant $(F(1,147)=8.46, p<0.01)$, but the main effects of regulatory focus $(F(1,147)=0.55, p>0.05)$ and invested resource $(F(1,147)=2.88, p>0.05)$ were not significant. Simple effect tests showed that for promotion-focused participants, the self-concept connection score when time investment was emphasized $(M=17.67, S D=3.25)$ was greater than when money investment was emphasized $(M=15.00, S D=4.41$, $F(1,148)=10.63, p<0.01)$, whereas for prevention-focused participants, the self-concept connection score when time investment was emphasized $(M=16.41, S D=3.15)$ was not different from when money investment was emphasized $(M=17.11, S D=3.29, F(1,148)=0.70, p>0.05)$.

Next, the mediating role of self-concept connection was tested by using the analysis outlined by Muller et al. (2005) for mediated moderation (Muller Judd \& Yzerbyt, 2005). Gender, types of invested resources, and regulatory focus were dummy coded $(\mathrm{male}=1$, female $=0$; time $=1$, money $=0$; promotion-focused $=1$, prevention-focused $=0$ ). Other variables' values were the scores of the corresponding items or scales in the questionnaire. The results of the regression equations are shown in Table 4.

Table 4. Regression coefficients for the mediated moderation analyses

\begin{tabular}{|c|c|c|c|c|c|c|}
\hline & $\begin{array}{l}\text { (1) } \\
\text { recommen } \\
\text { dation }\end{array}$ & $\begin{array}{l}\text { (2) } \\
\text { self-concept } \\
\text { connection }\end{array}$ & $\begin{array}{l}(3) \\
\text { recommend } \\
\text { ation }\end{array}$ & $\begin{array}{l}\text { (4) } \\
\text { complaint }\end{array}$ & $\begin{array}{l}\text { (5) } \\
\text { self-concept } \\
\text { connection }\end{array}$ & $\begin{array}{l}\text { (6) } \\
\text { complaint }\end{array}$ \\
\hline Gender & -0.15 & -0.00 & $-0.15^{*}$ & 0.06 & 0.02 & 0.06 \\
\hline $\begin{array}{l}\text { Importance of } \\
\text { time/money }\end{array}$ & -0.02 & 0.17 & -0.06 & 0.12 & $0.18 *$ & 0.12 \\
\hline Experience & 0.02 & -0.13 & 0.04 & 0.13 & 0.06 & 0.13 \\
\hline Types of resources & -0.08 & -0.12 & -0.05 & $-0.25^{*}$ & -0.18 & $-0.25^{*}$ \\
\hline Regulatory focus & 0.20 & $-0.24 *$ & 0.51 & -0.13 & $-0.27 *$ & -0.13 \\
\hline $\begin{array}{l}\text { Types of resources x } \\
\text { regulatory focus }\end{array}$ & $0.33^{*}$ & $0.39 * *$ & 0.25 & $0.40 * *$ & $0.39 * *$ & $0.40 * *$ \\
\hline Self-concept connection & & & $0.28 *$ & & & -0.01 \\
\hline $\begin{array}{l}\text { Self-concept connection } \\
\mathrm{x} \text { regulatory focus }\end{array}$ & & & -0.28 & & & 0.00 \\
\hline$R^{2}$ & 0.23 & 0.11 & 0.28 & 0.10 & 0.10 & 0.10 \\
\hline Adjusted $R^{2}$ & 0.20 & 0.08 & 0.24 & 0.06 & 0.07 & 0.04 \\
\hline
\end{tabular}

Note: The above regression coefficients are standardized regression coefficients $* p<0.05, * * p<0.01$.

The frequency of recommendation was regressed against the interaction of types of resources and regulatory focus $(\beta=0.33, t(144)=2.54, p<0.05)$ in the first regression equation. In the second regression equation, self-concept connection was regressed against the interaction of types of resources and regulatory focus $(\beta=0.39$, $t(144)=2.79, p<0.01)$. In the third regression equation, frequency of recommendation was regressed against self-concept connection $(\beta=0.28, t(142)=2.45, p<0.05)$. Neither the interaction of types of resources and regulatory focus nor the interaction of self-concept connection and regulatory focus was significant $\left(p_{\mathrm{s}}>0.05\right)$. Compared to the first equation, the adjusted $R^{2}$ of the third equation increased when self-concept connection was included. These results show that self-concept connection mediates the moderating role of regulatory focus in the relationship between types of invested resources and frequency of recommendations.

The frequency of complaint was regressed against the interaction of types of resources and regulatory focus $(\beta=0.40, t(144)=2.82, p<0.01)$ in the fourth regression equation. In the fifth regression equation, self-concept connection was regressed against the interaction of types of resources and regulatory focus $(\beta=0.39, t(144)=2.76$, 
$p<0.01)$. In the sixth regression equation, frequency of complaint was regressed against the interaction of types of resources and regulatory focus $(\beta=0.40, t(142)=2.74, p<0.01)$, with self-concept connection included; it did not predict complaint frequency $(\beta=-0.01, t(144)=-0.08, p>0.05)$. The interaction self-concept connection and regulatory focus also did not predict complaint frequency $(\beta=0.00, t(144)=0.01, p>0.05)$. Compared to the fourth equation, the adjusted $R^{2}$ of the sixth equation was reduced when self-concept connection was included. These results showed that self-concept connection did not mediate the moderating role of regulatory focus in the relationship between types of invested resources and frequency of complaints.

\subsection{Discussion}

The results of study 3 showed that promotion-focused customers made more recommendations and complaints when time investment (vs. money investment) was emphasized. However, prevention-focused customers made the same number of recommendations and complaints whether time or money investments were emphasized. These results support H2. Self-concept connection mediated the moderating role of customer regulatory focus in the relationship between customer's invested resources and recommendation behavior. For complaints, however, the mediating role of self-concept connection did not exist. This partially supported H3. These results showed that the theoretical model used in the current research was applicable to recommendation behavior, but not fully validated for complaint behavior. This might suggest that the underlying mechanisms of positive and negative CEBs are not the same. In fact, compared to positive CEB, scholars have suggested that negative CEBs (e.g., complaints) might have more complex cognitive and emotional processes (Stephens \& Gwinner, 1998).

In addition, study 3 showed that promotion-focused customers made stronger self-concept connection when time investment (vs. money investment) was emphasized. Prevention-focused customers made the same degree of self-concept connection whether they invested time or money. These results partially supported H1. Customer's time and money investments would manifest different self-concept connections only in special people, such as promotion-focused customers.

\section{General Discussion}

\subsection{Results and Discussion}

The results of three studies also show that: (1) customer's time and money investments can activate the self-concept connection to product/brand in shopping experience, and self-concept connection activated by time (vs. money) investment is greater only for promotion-focused customer. (2) Customers' regulatory focus moderates the relationship between the types of customer-invested resources (time vs. money) and CEBs (recommendation and complaint). For recommendations, the moderating effect is mediated by self-concept connection; however, for complaints, self-concept connection does not mediate the moderating effect. The current research results will facilitate the understanding of CEBs from the customer's perspective.

The current research showed that time and money have personality attributes (self-concept connection)which can influence customer's CEBs. In our studies, simply emphasizing either time or money invested in a shopping experience led to different self-concept connection and CEBs. As noted earlier, this time versus money effect has been found in numerous contexts. It is worth noting that the time vs. money effect on CEB is influenced by customers' personality traits (e.g., regulatory focus). The time versus money effect in our research only occurred for promotion-focused customers, not for prevention-focused customers, suggesting that the time versus money effect only occurs in some individuals. The current research results will facilitate the understanding of the relationship between time, money and CEBs.

\subsection{Implications for Marketing Management}

CEBs can have great effect on firm performance. How to encourage customers to generate more positive CEBs has become an important topic for firms. Our research finds that promotion-focused customers tend to initiate more positive CEBs when the time they invest is emphasized in satisfactory shopping experiences. This has an interesting implication for firms: in addition to providing excellent products or services, firms need to emphasize the time that customers spend when shopping for these items. Although customers always both invest time and money when shopping, merely emphasizing the customers' time investment can greatly increase CEBs, especially for promotion-focused customers. In addition, firms might encourage an increase in the customer's time investment through various channels. For example, firms can design product/service experience activities, provide communication platforms, build online communities, provide self-service technology and revisit customers.

Our results show that increasing the connection between customers' self-concept and products (or brands) becomes an important means to increase positive CEB. Therefore, how to increase the connection between 
customers' self-concept and products/brands has become an important topic. Shaping a unique brand image and building the connection between brand and some particular self-concept (e.g., masculinity; Sentis \& Markus, 1986) may be one feasible method of doing so. Building a brand image based on emotional appeal (not on rational appeal) or personality association (vs. functional association) may be another feasible method.

Our findings also suggest that the customers' regulatory focus is an important factor affecting CEB. In general, our studies show that promotion-focused customers initiate more positive CEB (e.g., recommendations) than prevention-focused customers. As this is a long-term and stable characteristic, firms could establish databases that include customers' trait regulatory focus by tracking customers' behavioral strategies and outcome sensitivities. For example, firms could note whether the customer focused on the product warranty (prevention-focused) or product upgrades (promotion-focused). When companies launch marketing activities to prompt positive CEB, they could use these databases to focus on promotion-focused customers, thereby hopefully creating far better word of mouth.

\subsection{Limitations and Future Research}

The current research has some limitations. The main variable in this research is the type of customer-invested resources (time vs. money). Customers investing different resources may lead to different CEB, but this may in turn be affected by the relative resource endowments of customers (Van Doorn et al., 2010). For example, customers with an abundance of time may be more likely to engage in online communities and blogging. In contrast, customers with a shortage of money may not make monetary donations to a brand-related charity. Future research needs to consider the effect of customers' resource endowments on CEB.

Study 3 attempts to explain the time vs. money effect on CEB. However, our theoretical model does not fully reveal the cause of the effect. In other words, the self-concept connection cannot fully explain this effect on CEB. Self-concept connection only mediates the relationship between the joint effects of customer-invested resources and regulatory focus on recommendations, but the mediating role of self-concept connection does not exist for complaints. In addition to the self-concept connection, other variables may effectively explain the time vs. money effect on positive and negative CEBs. Therefore, further research needs to consider other theoretical models to explain the phenomenon effectively.

The current research focused on customer recommendation and complaint behaviors. In fact, CEB includes many other types of behavior, for example, blogging and web posting (Chevalier \& Mayzlin, 2006; Hennig-Thurau et al., 2004). The current research selects only one example of such behavior as an indicator, as there is no well-defined scale to measure overall CEB. To better understand the influence of customer-based factors on CEB, there is a need to develop a scale that effectively measures overall CEB.

The Chinese context of the research also should be noted. Chinese culture emphasizes an interdependent view of the self, where one's status depends on membership in a larger social group. People with interdependent selves are motivated to fit in with relevant others and to become part of various interpersonal relationships. However, Western cultures emphasize an independent view of the self. The principal goal of the interdependent self is to maintain connectedness and harmony with others, and the principal goal of the independent self is uniqueness or standing out from the group (Markus \& Kitayama, 1991, 1994). Therefore, Chinese culture may inhibit the expression of self-concept, and Western cultures may encourage the expression of self-concept. Will culture (e.g., Asian culture vs. Western culture) affect the time versus money effect on CEB?

CEB may be directed towards many different audiences, such as friends, family, company employees, and strangers. Studies indicate that the strength of the relationship has an effect on the likelihood of recommendation (Ryu \& Feick, 2007) and word-of-mouth transmissions (Packard \& Wooten, 2013). The research scenarios used here are recommending or complaining to "good friends" or "the people around you," but do not discuss other possible relationships, for example "strangers." Future research could investigate whether CEB is different when it is directed at people with differing relationships. The CEBs in this study are directed at other customers. Another question to be addressed is, "What would happen when CEBs are directed to companies?"

\section{Acknowledgements}

This research was supported by the Social Science Foundation of China (17CGL022).

\section{References}

Belk, R. W. (1988). Possessions and the extended self. Journal of Consumer Research, 15(2), 139-162. https://doi.org/10.1086/209154

Brady, M. K., Voorhees, C. M., Cronin Jr, J. J., \& Bourdeau, B. L. (2006). The good guys don't always win: the 
effect of valence on service perceptions and consequences. Journal of Services Marketing, 20(2), 83-91. https://doi.org/10.1108/08876040610657011

Carstensen, L. L., Isaacowitz, D. M., \& Charles, S. T. (1999). Taking time seriously: a theory of socioemotional selectivity. American Psychologist, 54(3), 165-181. https://doi.org/10.1037/0003-066X.54.3.165

Chevalier, J. A., \& Mayzlin, D. (2006). The effect of word of mouth on sales: online book reviews. Journal of marketing research, 43(3), 345-354. https://doi.org/10.1509/jmkr.43.3.345

Daryanto, A., de Ruyter, K., Wetzels, M., \& Patterson, P. G. (2010). Service firms and customer loyalty programs: a regulatory fit perspective of reward preferences in a health club setting. Journal of the Academy of Marketing Science, 38(5), 604-616. https://doi.org/10.1007/s11747-009-0165-x

De Matos, C. A., \& Rossi, C. A. V. (2008). Word-of-mouth communications in marketing: a meta-analytic review of the antecedents and moderators. Journal of the Academy of Marketing Science, 36(4), 578-596. https://doi.org/10.1007/s11747-008-0121-1

Fournier, S. (1998). Consumers and their brands: developing relationship theory in consumer research. Journal of consumer research, 24(4), 343-353. https://doi.org/10.1086/209515

Freitas, A. L., \& Higgins, E. T. (2002). Enjoying goal-directed action: the role of regulatory fit. Psychological Science, 13(1), 1-6. https://doi.org/10.1111/1467-9280.00401

Haggard, P., Clark, S., \& Kalogeras, J. (2002). Voluntary action and conscious awareness. Nature Neuroscience, 5(4), 382-385. https://doi.org/10.1038/nn827

Hennig-Thurau, T., Gwinner, K. P., Walsh, G., \& Gremler, D. D. (2004). Electronic word-of-mouth via consumer-opinion platforms: what motivates consumers to articulate themselves on the internet? Journal of interactive marketing, 18(1), 38-52. https://doi.org/10.1002/dir.10073

Higgins, E. T. (1997). Beyond pleasure and pain. American Psychologist, 52(12), 1280-1300. https://doi.org/10.1037/0003-066X.52.12.1280

Higgins, E. T., Friedman, R. S., Harlow, R. E., Idson, L. C., Ayduk, O. N., \& Taylor, A. (2001). Achievement orientations from subjective histories of success: promotion pride versus prevention pride. European Journal of Social Psychology, 31(1), 3-23. https://doi.org/10.1002/ejsp.27

Hwang, J., \& Kandampully, J. (2012). The role of emotional aspects in younger consumer-brand relationships. Journal of Product \& Brand Management, 21(2), 98-108. https://doi.org/10.1108/10610421211215517

Leclerc, F., Schmitt, B. H., \& Dube, L. (1995). Waiting time and decision making: is time like money? Journal of Consumer Research, 22(1), 110-119. https://doi.org/10.1086/209439

Lee, B. (2012). Marketing Is Dead. Harvard Business Review [viitattu 1.11. 2012]. Retrieved from http://blogs.hbr. org/cs/2012/08/marketing_is_dead.html

Liu, W., \& Aaker, J. (2007). Do you look to the future or focus on today? The impact of life experience on intertemporal decisions. Organizational Behavior and Human Decision Processes, 102(2), 212-225. https://doi.org/10.1016/j.obhdp.2006.02.004

Lockwood, P., Jordan, C. H., \& Kunda, Z. (2002). Motivation by positive or negative role models: regulatory focus determines who will best inspire us. Journal of personality and social psychology, 83(4), 854-864. https://doi.org/10.1037/0022-3514.83.4.854

Markus, H. R. (1977). Self-schemata and processing information about the self. Journal of Personality and Social Psychology, 35(2), 63-78. https://doi.org/10.1037/0022-3514.35.2.63

Markus, H. R., \& Kitayama, S. (1991). Culture and the self: Implications for cognition, emotion, and motivation. Psychological Review, 98(2), 224-253. https://doi.org/10.1037/0033-295X.98.2.224

Markus, H. R., \& Kitayama, S. (1994). A collective fear of the collective: Implications for selves and theories of selves. Personality and Social Psychology Bulletin, 20(5), 568-579. https://doi.org/10.1177/0146167294205013

Mogilner, C. (2010). The pursuit of happiness time, money, and social connection. Psychological Science, 21(9), 1348-1354. https://doi.org/10.1177/0956797610380696

Mogilner, C., \& Aaker, J. (2009). "The time vs. money effect”: Shifting product attitudes and decisions through personal connection. Journal of Consumer Research, 36(2), 277-291. https://doi.org/10.1086/597161 
Muller, D., Judd, C. M., \& Yzerbyt, V. Y. (2005). When moderation is mediated and mediation is moderated. Journal of personality and social psychology, 89(6), 852-863. https://doi.org/10.1037/0022-3514.89.6.852

Packard, G. M., \& Wooten, D. B. (2013). Compensatory knowledge signaling in consumer word-of-mouth. Journal of Consumer Psychology, 23(4), 434-450. https://doi.org/10.1016/j.jcps.2013.05.002

Prince, M. (1993). Self-concept, money beliefs and values. Journal of Economic Psychology, 14(1), 161-173. https://doi.org/10.1016/0167-4870(93)90044-L

Reed, A., Aquino, K., \& Levy, E. (2007). Moral identity and judgments of charitable behaviors. Journal of Marketing, 71(1), 178-193. https://doi.org/10.1509/jmkg.71.1.178

Rust, R. T., Lemon, K. N., \& Zeithaml, V. A. (2004). Return on marketing: using customer equity to focus marketing strategy. Journal of marketing, 68(1), 109-127. https://doi.org/10.1509/jmkg.68.1.109.24030

Ryu, G., \& Feick, L. (2007). A penny for your thoughts: referral reward programs and referral likelihood. Journal of Marketing, 71(1), 84-94. https://doi.org/10.1509/jmkg.71.1.84

Saini, R., \& Monga, A. (2008). How I decide depends on what I spend: use of heuristics is greater for time than for money. Journal of Consumer Research, 34(6), 914-922. https://doi.org/10.1086/525503

Sentis, K.,\& Markus, H. (1986). Brand Personality andSelf. In Jerry, C. O., \& Keith, S. (Eds.), Advertising and Consumer Psychology, Vol. 3, pp. 132-148.New York: Praeger,

Soman, D., \& Lam, V. M. (2002). The effects of prior spending on future spending decisions: the role of acquisition liabilities and payments. Marketing Letters, 13(4), 359-372. https://doi.org/10.1023/A:1020374617547

Stephens, N., \& Gwinner, K. P. (1998). Why don't some people complain? A cognitive-emotive process model of consumer complaint behavior. Journal of the Academy of Marketing science, 26(3), 172-189. https://doi.org/10.1177/0092070398263001

Van Doorn, J., Lemon, K. N., Mittal, V., Nass, S., Pick, D., \& Pirner, P. et al. (2010). Customer engagement behavior: theoretical foundations and research directions. Journal of Service Research, 13(3), 253-266. https://doi.org/10.1177/1094670510375599

Vohs, K. D., Mead, N. L., \& Goode, M. R. (2006). The psychological consequences of money. Science, 314(5802), 1154-1156. https://doi.org/10.1126/science.1132491

Vohs, K. D., Mead, N. L., \& Goode, M. R. (2008). Merely activating the concept of money changes personal and interpersonal behavior. Current Directions in Psychological Science, 17(3), 208-212. https://doi.org/10.1111/j.1467-8721.2008.00576.x

Wittmann, M. (2009). The inner experience of time. Philosophical Transactions of the Royal Society B, 364(1525), 1955-1967. https://doi.org/10.1098/rstb.2009.0003

Zauberman, G., \& Lynch Jr, J. G. (2005). Resource slack and propensity to discount delayed investments of time versus money. Journal of Experimental Psychology: General, 134(1), 23-37. https://doi.org/10.1037/0096-3445.134.1.23

Zhang, L. (2009). An exchange theory of money and self-esteem in decision making. Review of General Psychology, 13(1), 66-76. https://doi.org/10.1037/a0014225 


\section{Appendixes}

Appendix A. Revised self-concept connection scale

CFA of the modified self-concept connection scale $(\mathrm{N}=170)$

\begin{tabular}{|c|c|c|c|}
\hline Items & $\begin{array}{l}\text { Factor } \\
\text { loading }\end{array}$ & Cronbach's $\alpha$ & $\begin{array}{l}\text { Composite } \\
\text { reliability }\end{array}$ \\
\hline Self-concept connection scale & & 0.81 & 0.82 \\
\hline 1. These products (or brands) and I have a lot in common. & $0.76 * * *$ & & \\
\hline $\begin{array}{l}\text { 2. These products' (or brands') images and my self-image are similar in a lot } \\
\text { of ways. }\end{array}$ & $0.77 * * *$ & & \\
\hline 3. These products (or brands) say a lot about the kind of person I am. & $0.72 * * *$ & & \\
\hline 4. These products (or brands) say a lot about the kind of person I want to be. & $0.61 * * *$ & & \\
\hline 5. These products (or brands) are a part of me. & $0.57 * * *$ & & \\
\hline
\end{tabular}

Note: The numbering of the items is taken from the original self-concept connection scale.

$* * * p<0.001$.

We carried out a confirmatory factor analysis (CFA) of the modified self-concept connection scale to test its validity using AMOS 17.0. The CFA model fit was deemed acceptable on the basis of a battery of fit indexes $\left(\chi^{2}=33.601, d f=5, G F I=0.926, A G F I=0.777, C F I=0.900, I F I=0.902\right.$, and $\left.R M S E A=0.184\right)$. All of the path coefficients were significant at $\alpha=0.001$ level. The standardized factor loadings of the items were all above 0.5 (0.57 0.77). The Cronbach's $\alpha$ coefficients and composite reliabilities of the scale were all above 0.7 (0.81 0.82).

The results suggested that the modified regulatory focus scale was acceptable.

Appendix B. Revised regulatory focus questionnaire

CFA of the modified regulatory focus questionnaire (RFQ) $(\mathrm{N}=357)$

\begin{tabular}{|c|c|c|c|}
\hline Items & $\begin{array}{l}\text { Factor } \\
\text { loading }\end{array}$ & $\begin{array}{c}\text { Cronbach's } \\
\alpha \\
\end{array}$ & $\begin{array}{l}\text { Composite } \\
\text { reliability }\end{array}$ \\
\hline Regulatory focus questionnaire & & 0.80 & 0.90 \\
\hline Promotion-focused subscale & & 0.79 & 0.79 \\
\hline 1. Compared to most people, I typically get what I want out of life. & $0.62 * * *$ & & \\
\hline 3. I always accomplish things when I get 'psyched' to work even harder. & $0.55 * * *$ & & \\
\hline 7. I often do well at different things that I try. & $0.61 * * *$ & & \\
\hline $\begin{array}{l}\text { 9. When it comes to achieving things that are important to me, I find that I } \\
\text { perform as well as I ideally would like to do. }\end{array}$ & $0.56^{* * *}$ & & \\
\hline 10. I feel like I have made progress toward being successful in my life. & $0.73 * * *$ & & \\
\hline $\begin{array}{l}\text { 11. I have found many hobbies or activities in my life that capture my interest } \\
\text { and motivate me to put effort into them. }\end{array}$ & $0.67 * * *$ & & \\
\hline Prevention-focused subscale & & 0.85 & 0.86 \\
\hline $\begin{array}{l}\text { 2. Growing up, I always 'cross the line' by doing things that my parents would } \\
\text { not tolerate. }\end{array}$ & $0.67 * * *$ & & \\
\hline 4. I often got on my parents' nerves when I was growing up. & $0.86 * * *$ & & \\
\hline $\begin{array}{l}\text { 5. I often disobeyed the rules and regulations that were established by my } \\
\text { parents. }\end{array}$ & $0.91 * * *$ & & \\
\hline $\begin{array}{l}\text { 6. Growing up, I always acted in ways that my parents thought were } \\
\text { objectionable. }\end{array}$ & $0.69 * * *$ & & \\
\hline 8. Not being careful enough has gotten me into trouble at times. & $0.53 * * *$ & & \\
\hline
\end{tabular}

Note: The numbering of the items is taken from the original regulatory focus questionnaire.

$* * * p<0.001$.

We carried out a confirmatory factor analysis (CFA) of the modified RFQ to test its validity using AMOS 17.0. The CFA model fit was deemed acceptable on the basis of a battery of fit indexes $\left(\chi^{2}=109.605, d f=43\right.$, $G F I=0.948, A G F I=0.921, C F I=0.952, N F I=0.924, I F I=0.953$, and $R M S E A=0.066)$. All of the path coefficients were significant at $\alpha=0.001$ level. The standardized factor loadings of the items were all above $0.5(0.53 \sim 0.91)$. The Cronbach's $\alpha$ coefficients and composite reliabilities of the scale and the two subscales were all above 0.7 (0.79 0.90). The results suggested that the modified regulatory focus scale was acceptable.

\section{Copyrights}

Copyright for this article is retained by the author(s), with first publication rights granted to the journal.

This is an open-access article distributed under the terms and conditions of the Creative Commons Attribution license (http://creativecommons.org/licenses/by/4.0/). 